\title{
The relationship between knowledge of oral health-related issues and the DMFT index in 12-year-old students in Rafsanjan, Iran, in 2016
}

\author{
Shakerian M, DDS, $\mathrm{MS}^{1 *}$, Sardari F, DDS, $\mathrm{MS}^{2}$, Kordafshari T, DDS, $\mathrm{MS}^{3}$ \\ 1- Assistant Prof., Dept. of Operative Dentistry, School of Dentistry, Rafsanjan University of Medical Sciences, Rafsanjan, Iran. \\ 2- Assistant Prof., Dept. of Oral Medicine, School of Dentistry, Rafsanjan University of Medical Sciences, Rafsanjan, Iran. \\ 3-Assistant Prof., Dept. of Operative Dentistry, School of Dentistry, Golestan University of Medical Sciences, Golestan, Iran.
}

\begin{abstract}
Received: September 2016, Accepted: October 2016

Background: Children are the most sensitive and vulnerable group in terms of tooth decay. Any change or improvement in health-related knowledge and behavior in this group can have long-term and significant impacts on the health of the future generation. Thus, the present study was conducted with the aim to determine the relationship of knowledge of oral health-related issues with the decayed, missing, and filled teeth (DMFT) index in 12-year-old students of Rafsanjan, Iran, in 2016.

Materials and Methods: This descriptive, cross-sectional study was performed on 460 students (230 boys and 230 girls) of 12 years of age from 10 elementary schools in Rafsanjan. The subjects were randomly selected. Data were collected through clinical examination, interviews, and a questionnaire. The questionnaire consisted of two parts; the first part contained a demographic characteristics form, and the second part contained the DMFT index and questions on knowledge of oral health-related issues. Data were analyzed using independent t-test, ANOVA, chi-square, and the Pearson correlation coefficient $(\alpha=$ $0.05)$.

Results: Mean DMFT index and knowledge score of the students were $2.66 \pm 1.40$ and $5.43 \pm 1.82$, respectively. Students with higher knowledge had lower DMFT index. Moreover, mean knowledge score of students with homemaker mothers was significantly higher compared to students with working mothers.

Conclusion: The results of this study suggested a positive significant relationship between knowledge of oral health-related issues and DMFT index in 12-year-old students of Rafsanjan.
\end{abstract}

Keywords: Knowledge, Oral Hygiene, Awareness, Dental Caries

\section{Introduction}

Tooth decay is a bacterial disease of calcified dental tissues which causes the demineralization of inorganic matter and destruction of organic matter. Factors which cause tooth decay can be divided into 3 groups related to the host (saliva, composition, and tooth structure), environmental factors (nutrition and fluoride) and microorganisms (1). Tooth decay, as a multifactorial bacterial disease, is greatly affected by other factors such as parental education, family economic status, number of family members, and level of oral hygiene maintenance (2). Oral hygiene has obtained much attention in regards to provision and improvement of public health to the extent that it is now recognized as one of the main 11 slogans of the $21^{\text {st }}$ century (3). On the other hand, correct understanding of the oral status and treatment needs of different age groups is one of the most

\footnotetext{
* Corresponding author: Mohadeseh Shakerian, Dept of Operative Dentistry, School of Dentistry, Rafsanjan University of Medical Sciences, Rafsanjan, Iran.

E-mail: m.shakerian@rums.ac.ir
} 
important factors in health-treatment planning. Today, correct and accurate information comparable to international standards attract the attention of researchers and planners. The determination of different indices related to oral health status in different time periods and age and social groups is necessary to obtain an accurate depiction of the current situation that can be compared with the objectives of the FDI World Dental Federation (4). The most important index for the determination of the prevalence of tooth decay in a population is the decay, missing, and filled teeth (DMFT) index. To calculate the DMFT of a society, the total number of permanent decayed, extracted, and filled teeth of each individual in that society is counted and its mean is calculated. DMFT is a simple, rapid, and quantifiable index in dentistry which has been used for many decades (5). Determination of DMFT and other indices enables societies to expand their plans toward the prevention or treatment of oral diseases. Calculation of indices related to tooth decay for 12-year-old children is one of the recommendations of the World Health Organization (WHO). Any change or improvement in health knowledge and behavior can have long-term and significant impacts on the health of the future generation. Furthermore, the resulting data is used as foundational statistics to determine the treatment requirements of the studied society, for unbiased distribution of health and treatment facilities, and management of dentistry prevention programs for the development of comprehensive health programs (6). Sadeghi studied the prevalence of decayed permanent first molar among 12-year-old students in Rafsanjan, Iran, in 2007 (7). He found that mean DMFT of the permanent first molar was $1.9 \pm 1.6$, and girls had more decayed teeth compared to boys (7). Mirzaei et al. conducted a study on the knowledge, attitude, and action of students of elementary schools in Yazd, Iran, regarding oral hygiene (8). They concluded that the knowledge, attitude, and action of students regarding oral hygiene were at an average level. In addition, the students reported their health coach and teachers as their most important source of information (8). Peng et al. performed a study with the aim of describing the oral health status of urban 12-year-old students, evaluating their behavior and attitudes regarding oral hygiene, and assessing the effect of socio-economic factors on tooth decay (9). They reported that children living in the center of a city obtained most of their information on oral hygiene from dentists and teachers and had a significant difference with children in rural areas in this respect. However, no significant difference was observed between boys and girls in this regard (9). The present study was undertaken with the aim of the evaluation of oral health status and determination of the relationship of knowledge of oral health-related issues with the DMFT index in 12-year-old students of Rafsanjan in 2016.

\section{Materials and Methods}

This descriptive, cross-sectional study was conducted on 12-year-old students of Rafsanjan. Based on a similar study (10) and sample volume equation, 460 students (230 girls and 230 boys) were randomly selected as study subjects. All students who were identified as medically healthy in the preliminary evaluation based on health records available at the school, were Iranian citizens, and resided in Rafsanjan were entered into the study. Students with systemic diseases or mental disorders were eliminated from the study. The participants' age was recorded based on date of birth. The data were collected through clinical examinations, interviews, and a joint questionnaire by the Ministry of Health and Ministry of Education (11). The questionnaire consisted of two parts. The first part consisted of demographic characteristics such as gender, education level, 
parental occupation, and order of child's birth. The second part contained questions on the knowledge of oral health issues, such as brushing, flossing, and fluoride and cariogenic food use, and information regarding the DMFT index. To determine tooth decay, the WHO definition was used; destruction in the form of visible cavities on the smooth surface or grooves of the teeth and the floor or soft visible wall of tooth enamel. Restored teeth with recurring caries and teeth filled with temporary material were also included in this category. Suspicious areas and white spots were not considered as tooth decay. Missing teeth were only recorded if they were extracted because of decay; teeth that were extracted due to traumatic or non-traumatic causes such as orthodontics were not included in this category. Teeth with 1 or more permanent, intact restorations without caries were recorded as filled teeth. Regarding proximal surfaces, if the tip of the probe entered the cavity it was recorded as tooth decay, if there was any doubt, it was considered as a healthy tooth (7). To determine the level of knowledge of the subjects, their correct responses to questionnaire items (10 questions) received 1 point and incorrect responses received 0 points. Total knowledge score of less than 5 demonstrated poor knowledge, 5-7 average knowledge, and higher than 7 good knowledge. Data were analyzed in SPSS software (version 23, SPSS Inc., Chicago, IL, USA), and results of quantitative variables was presented as mean \pm $\mathrm{SD}$ and qualitative variables as number (\%). Mean dental parameters were compared using independent t-test and ANOVA, and qualitative variables were compared using chi-square test. The Pearson correlation coefficient was used to determine the relationship between students' knowledge score and DMFT index. Significant level was determined as less than or equal to 0.05 in all tests.

\section{Results}

Mean total DMFT index of students was $2.66 \pm$ 1.40 and mean DMFT index of boys and girls was, respectively, $2.61 \pm 1.35$ and $2.71 \pm 1.45$ $(\mathrm{P}=0.443)$ (Table 1).

Table 1: Prevalence of decayed, missing, and filled teeth index and its components (decayed, extracted, and restored permanent teeth) among 12-year-old students of Rafsanjan in 2016

\begin{tabular}{|c|c|c|c|c|}
\hline Index & Decay & Extracted & Restored & DMFT \\
\hline Gender & \multicolumn{4}{|c|}{ Mean \pm SD } \\
\hline Boys & $\begin{array}{c}1.38 \pm 0.90 \\
53 \%\end{array}$ & $\begin{array}{c}0.47 \pm 0.63 \\
18 \%\end{array}$ & $\begin{array}{c}0.76 \pm 0.69 \\
29 \%\end{array}$ & $2.61 \pm 1.35$ \\
\hline Girls & $\begin{array}{c}1.27 \pm 0.94 \\
46 \%\end{array}$ & $\begin{array}{c}0.38 \pm 0.53 \\
15 \%\end{array}$ & $\begin{array}{c}1.06 \pm 0.84 \\
39 \%\end{array}$ & $2.71 \pm 1.45$ \\
\hline total & $\begin{array}{c}1.33 \pm 0.92 \\
50 \%\end{array}$ & $\begin{array}{c}0.43 \pm 0.58 \\
16 \%\end{array}$ & $\begin{array}{c}0.90 \pm 0.78 \\
34 \%\end{array}$ & $2.66 \pm 1.40$ \\
\hline $\mathbf{P}$ & 0.223 & 0.094 & 0.001 & 0.443 \\
\hline
\end{tabular}

DMFT: decay, missing, and filled teeth

The results of the study showed that mean total knowledge score of students was $5.43 \pm 1.82$ and its mean among boys and girls was, respectively, $4.50 \pm 1.61$ and $6.37 \pm 1.52$. Mean knowledge score was significantly higher among girls compared to boys $(\mathrm{P}<0.001)$.
The results of students' knowledge score with consideration of their parents' educational and occupational status showed that the mean knowledge score of students with homemaker mothers was significantly higher than students with working mothers $(\mathrm{P}=0.009)$. No 
significant difference was observed in other related items (father's and mother's education and father's occupation $)(\mathrm{P}<0.050)$.

The results of the comparison of the DMFT index in each subgroup of poor, average, and high knowledge are presented in table 2 . The results presented in this table show that students with higher knowledge had lower DMFT index and students with lower knowledge had higher DMFT index. The comparison of boys and girls illustrated that girls had significantly better performance $(\mathrm{P}<0.001)$.

Table 2: Mean decayed, missing, and filled teeth index based on knowledge score among 12-yearl-old students in Rafsanjan in 2016

\begin{tabular}{ccccc}
\hline \multirow{2}{*}{ DMFT Knowledge } & Poor & Average & High & \multirow{2}{*}{ P-Value } \\
\cline { 2 - 4 } & & Mean \pm SD & \\
\hline Boys & $2.83 \pm 1.47$ & $2.46 \pm 1.14$ & $1.73 \pm 1.27$ & 0.009 \\
\hline Girls & $3.04 \pm 1.61$ & $2.87 \pm 1.31$ & $2.09 \pm 1.58$ & 0.001 \\
\hline Total & $2.87 \pm 1.49$ & $2.71 \pm 1.26$ & $2.03 \pm 1.53$ & 0.001 \\
\hline
\end{tabular}

DMFT: decay, missing, and filled teeth

Based on the results of table 3, although the students' knowledge score increased with increase in mothers' education level, this relationship was not statistically significant $(\mathrm{P}=$
0.117). Furthermore, with increase in order of birth, the students' knowledge score decreased; students with higher birth order had lower knowledge scores $(\mathrm{P}=0.001)$.

Table 3: The Pearson correlation coefficient of qualitative variables and knowledge score of 12-year-old students of Rafsanjan in 2016

\begin{tabular}{ccccc}
\hline & & $\begin{array}{c}\text { Fathers' } \\
\text { education }\end{array}$ & $\begin{array}{c}\text { Mothers' } \\
\text { education }\end{array}$ & $\begin{array}{c}\text { Birth order of the } \\
\text { student }\end{array}$ \\
\hline Knowledge score & rs & -0.029 & 0.075 & -0.153 \\
\cline { 2 - 5 }$($ poor, average, high) & P-value & 0.542 & 0.116 & 0.001 \\
\hline
\end{tabular}

* Correlation significant at 0.01 level

\section{Discussion}

Today, oral hygiene is a necessity and part of public health, and failure to maintain dental hygiene results in dental issues, disruption of public health, reduced self-esteem, chronic infections, and reduced quality of life (QOL), especially in children. Thus, this issue is a priority of the WHO in its chronic diseases prevention and health promotion programs (12, 13). The 6-12 years age group is prioritized in oral hygiene programs due to the high prevalence of tooth decay in this group, and the importance of this age group in terms of development of permanent teeth and formation of beliefs, habits, and lifestyle. Any change or improvement in the behavior of this age group can have long-term and significant impacts on the health of the future generation of the society. Some researchers believe that increased knowledge and awareness in this age group is the only method of oral hygiene improvement in the society. Furthermore, the simplest and most cost-effective method of implementing awareness and knowledge promotion programs is to execute them in schools (14-17).

Based on the results of the present study, students with higher knowledge level had lower DMFT index. The separation of gender groups proved this relationship to be also significant 
among both boys and girls. The study by Gauba et al. on 100 students of 10-12 years of age in India showed knowledge to be significantly correlated with performance, plaque index, gingival health, and tooth decay expansion rate after educational and treatment intervention (18). They found that knowledge level and tooth brushing behavior had increased and use of sugar, plaque index, gingival inflammation, and tooth decay expansion rate had decreased after their intervention (18). Lalic, in a study on 112 Serbian students of 12 years of age, found that mean decayed teeth decreased and mean restored teeth increased 6 months after the educational intervention (19). Moreover, this study showed that education increased motivation for self-care among students which, in turn, increases the oral health level (19).

The results of the present study showed that students' knowledge score with consideration of parents' occupational and educational status showed that this score was significantly higher among students with homemaker mothers compared to those with educated and working mothers. No significant difference was observed in other cases in this respect. Numerous studies have illustrated the role of parents in the prevention of oral diseases in their children. Poutanen et al. reported a significant relationship between parents' health behavior and their children's health behavior (20). The results of the study by Saied Mohammadi et al. also showed lower rate of tooth decay among children of mothers who maintained oral hygiene (21). Mitrankul et al. also reported parents' education level as an effective factor in their children's oral health (22). Costa believed that to ensure adequate oral health, parents' views of their children's health habits are important (23). Thus, it is evident that oral health hygiene and knowledge of parents has a positive impact on their children's oral health, and their knowledge and attitude regarding oral health can promote their children's oral health skills (24).

The current study results also showed that knowledge of oral health-related issues had an inverse relationship with birth order; with increase in birth order, knowledge score decreased. This finding was in agreement with that of the study by Javadinejad et al. who showed that with increase in the number of children in a family, the prevalence of tooth decay also increased (6). Increased birth order which is also indicative of increase in the number of family members can decrease the contribution of household income and parents' attention to each member (6).

Overcoming problems such as time limitation, high costs, and want of facilities and equipment is a barrier to oral treatments. The most important way to decrease and prevent oral diseases $(25,26)$ and the most important solution in this respect is the implementation of interventions related to health promotion and educational programs aiming at increasing students' knowledge (27). Application of different health education solutions based on novel learning methods and use of the most effective and rapid method for the promotion of oral health in children is of great importance. Through these methods, the rate of oral diseases can be decreased in this age group. In this respect, numerous studies have shown that, despite the many methods and patterns used in the execution of oral health promotion interventions in different countries, the most important principle of education and promotion of knowledge in order to reduce oral diseases is the consideration of lifestyle-related behavior (28-30). Lack of knowledge on oral health, maintenance of hygiene, and prevention of oral diseases will result in the loss of teeth at younger ages and more difficult and costly future outcomes. Lack of preventive measures, expansion of oral health services, and education on oral health in these children will result in the 
payment of high treatment costs, and provision of dental materials and expensive equipment and human resources in oral treatments by families and the government $(31,32)$.

\section{Conclusion}

The results of the present study suggested the presence of a significant relationship between knowledge of oral health issues and DMFT index in 12-year-old students of Rafsanjan. High rate of knowledge can have a positive effect on the health behavior of students, and these health behaviors are effective on oral health.

\section{Acknowledgement}

The authors wish to thank Dr. Mostafa Sadeghi for his valuable advice.

Conflict of interest: None declared

\section{References}

1- Shariati B. Oral Health. In: Hatami H, Razavi SM, Eftekhar AH, Majlesi F. Textbook of public health. $3^{\text {rd }}$ ed. Tehran: Arjmand; 2013. (Vol 1).

2- du Plessis JB. The effect of socio-economic status on dental caries experience in 6,12 and 15 years old school children in Port Elizabeth. J Dent Assoc S Afr 1997; 52(7): 483-6.

3- Samadzadeh H, Hesari H, Noori M. A survey on the DMFT trends in 6 to 13 years Old Iranian school children in 1999. Journal of Dental School 2001: 19(3):262-72.

4- Leite IC, Ribeiro RA. Dental caries in the primary dentition in Public nursery school children in Juiz de Fora Minas Geruis, Brazil. Cad Saude Publica 2000; 16(3):717-22.

5- Mehrdad K. International Epidemiological Indices In dentistry Research Suggested by WHO. $1^{\text {st }}$ ed. Tehran: ACECR, Shahid Beheshti University of Medical Sciences; 1988.

6- Javadinejad sh, Karami M, Azizi HR. Caries prevalence in 12-year-old children of Isfahan city expressed by the significant caries index. Journal of Isfahan Dental School 2006; 2(2):13-17.

7- Sadeghi M. Prevalence and bilateral occurrence of first permanent molars caries in 12-year-old students. J Dent Res Dent Clin Dent Prospects 2007;1(2):86-92.

8- MirzaeiAlavijeh M, Jalilian F, Baghiani Moghadam M, Hatamzadeh N, ZinatMotlagh F, Dahaghin N. Knowledge, attitude and practice of elementry shool students about oral health in yazd. Iranian Journal of Pediatric Dentistry 2013; 9(1):43-50.

9- Peng B, Petersen PE, Fan MW, Tai BJ. Oral health status and oral health behavior of 12-yearold urban school children in the people's republic of China. Community Dent Health 1997; 14(4):238-44.

10- Vakilzadeh Sh, Bastani P, Moosavifatemi N ,Hatemi B, Maschi M, Rahnama F, et.al. Knowledge about dental and oral health for teachers. $1^{\text {st }}$ ed. Tehran: Sarvnegar; 2010.

11- Lauris JR, da Silva Bastos R, de Magalhaes Bastos JR. Decline in dental caries among 12-year-old children in Brazil, 1980-2005. Int Dent J 2012; 62(6):308-14.

12- Brukiene V, Aleksejuniene J. An overview of oral health promotion in adolescents. Int $\mathrm{J}$ Paediatr Dent 2009; 19(3):163-71.

13- Fadel HT. Studies on the associations between dental caries, periodontal disease and different systemic conditions [PhD Thesis]. Gothenburg: University of Gothenburg; 2012.

14- de Farias IA, de Araújo Souza GC, Ferreira MA. A health education program for Brazilian public school children: the effects on dental health practice and oral health awareness. J Public Health Dent 2009; 69(4):225-30.

15- Amalia R, Schaub RM, Widyanti N, Stewart R, Groothoff JW. The role of school-based dental programme on dental caries experience in Yogyakarta Province, Indonesia. Int J Paediatr Dent 2012; 22(3):203-10.

16- Yazdani R, Vehkalahti MM, Nouri M, Murtomaa H. School-based education toimprove oral cleanliness and gingival health in adolescents in Tehran, Iran. Int J Paediatr Dent 2009; 19(4):27481.

17- Petersen PE. The World Oral Health Report 2003: continuous improvement of oral health in the 21 st century-the approach of the WHO global oral health programme. Community Dent Oral Epidemiol 2003; 31(Suppl 1):3-23.

18- Gauba A, Bal IS, Jain A, Mittal HCh. School based oral health promotional intervention: Effect on knowledge, practices and clinical oral health related parameters. Contemp Clin Dent 2013; 4(4):493-9. 
19- Lalić M, Aleksić E, Gajić M, Milić J, Malešević Đ. The efficacy of the interventional health education program for oral health improvement in school children. Stomatol Glas Srb 2012; 59(1):27-34.

20- Poutanen R, Lahti S, Tolvanen M, HausenH. Parental influence on children's oral healthrelated behavior. Acta Odontol Scand 2006; 64(5):286-92.

21- Saied-Moallemi Z, Murtomaa H, Tehranchi A, Virtanen JI. Oral health behavior of Iranian mothers and their 9-year-old children. Oral Health Prev Dent 2007; 5(4):263-9.

22- Mitrakul K, Laovoravit V, Vanichanuwat V, Charatchaiwanna A, Charatchaiwanna A, Bunpradit W, et al. Factors associated with parent capability on child's oral health care. Southeast Asian. J Trop Med Public Health 2012; 43(1):249-55.

23- Costa C, Pereira M, Passadouro R, Spencer B. Children's oral hygiene: healthy mouth, families supervise? Acta Med Port 2008; 21(5):467-74.

24- Vanagas G, Milašauskienè Z, Grabauskas V, Mickevičienè A. Associations between parental skills and their attitudes toward importance to develop good oral hygiene skills in their children. Medicina (Kaunas) 2009; 45(9):718-23.

25- Petersen PE. Global policy for improvement of oral health in the 21 st century-implications to oral health research of World Health Assembly 2007, World Health Organization. Community Dent Oral Epidemiol 2009; 37(1):1-8.
26- Jackson SL, Vann WF Jr, Kotch JB, Pahel BT, Lee JY. Impact of poor oral health on children's school attendance and performance. Am J Public Health 2011; 101(10):1900-6.

27- Buglar ME, White KM, Robinson NG. The role of self-efficacy in dental patients' brushing and flossing: testing an extended Health Belief Model. Patient Educ Couns 2010; 78(2):269-72.

28- Tai BJ, Jiang H, Du MQ, Peng B. Assessing the effectiveness of aschool-based oral health promotion programme in Yichang City, China. Community Dent Oral Epidemiol 2009; 37(5):391-8.

29- Jain A, Gupta J, Aggarwal V, Goyal C. To evaluate the comparative status of oral health practices, oral hygiene and periodontal status amongst visually impaired and sighted students. Spec Care Dentist 2013; 33(2):78-84.

30- Yi G, Hyun HJ. A study on knowledge of oral health, behavior, self-efficacy, belief, and the number of dental caries of elementary school students. Journal of Korean Academy of Community Health Nursing 2009; 20(4):531-9.

31- Chachra S, Dhawan P, Kaur T, Sharma A. The most effective and essential way of improving the oral health status education. J Indian Soc Pedod Prev Dent 2011; 29(3):216-21.

32- Ahn HY, Yi G. Application of dental health program for elementary school children. Journal of Korean Academy of Child Health Nursing 2010; 16(1):49-55. 